\title{
Responses of Groundwater Lowering Systems: Empirical Equations Via Field Records
}

\author{
Mona A. Mansour, Ahmed M. Samieh, Amr M. Radwan and Eslam A. Ahmed
}

\begin{abstract}
This study aims to evaluate the accuracy of analytical equations which are mostly used in the design of dewatering systems using deepwells. This is accomplished by analyzing the data obtained from dewatering systems executed in twenty different sites within the Egyptian Nile Valley and Delta. The studied cases included gravity flow (unconfined aquifer), artesian flow (confined aquifer) and mixed flow (semi-confined aquifer) cases. For each of the considered sites, the actual discharge from pumping drilled wells and the actual drawdown of the groundwater table were measured. Besides, a pumping test was performed at each of these sites. The field data was then analyzed by adopting the empirical analytical equations to assess the responses of groundwater to the implemented lowering systems. The obtained results showed that the actual monitored drawdown values were not in good agreement with the analytical results. Therefore, practical correlation factors, based on data from the investigated sites and a comprehensive parametric study, were derived to enhance the results of the analytical equations.

Hence, by implementing such cumulative drawdown correlation factors in the empirical equations, a more accurate assessment of the expected drawdown values can be attained. For aquifers within the Nile valley and Delta, average cumulative drawdown correlation factors of $0.7,0.65$ and 0.8 were found to be satisfactory for unconfined aquifers, confined aquifers, and semi-confined aquifers, respectively.
\end{abstract}

Keywords: Dewatering systems, groundwater flow, aquifers, analytical equations, pumping test, in-situ monitoring.

\section{INTRODUCTION}

Groundwater control is a significant issue with all underground constructions where it affects the structural design and the construction procedures, which reflect on the overall project budget. Determining the most effective solution to a groundwater issue can be enhanced through the understanding of groundwater flow phenomena and the methods of identifying and analyzing site specific conditions. Analysis of dewatering systems is mostly carried out using analytical formulae or numerical models, [1]. The first analytical solutions for the equations of groundwater flow in

Revised Manuscript Received on December 30, 2019.

* Correspondence Author

Mona A. Mansour*, Department of Civil Engineering, Helwan University, Cairo, Egypt. Email: MONAMANSOR@m-eng.helwan.edu.eg

Ahmed M. Samieh, Department of Civil Engineering, Helwan University, Cairo, Egypt. Email: abcan98@yahoo.com

Amr M. Radwan, Department of Civil Engineering, Helwan University, Cairo, Egypt. Email: amrrad@tedata.net.eg

Eslam A. Ahmed, Ministry of Housing, Utilities and Urban Communities, Egypt. Email: eng_eslam1980@yahoo.com

(C) The Authors. Published by Blue Eyes Intelligence Engineering and Sciences Publication (BEIESP). This is an open access article under the CC BY-NC-ND license (http://creativecommons.org/licenses/by-nc-nd/4.0/) aquifers subjected to pumping were provided by [2] for a steady-state, and by [3, 4] for a transient state. These solutions consider very restrictive conditions that limit their application to aquifers that are porous, uniform, homogeneous, infinite, of constant thickness and isotropic. They also assume pumping occurs in a fully penetrating well with a constant discharge, [5]. A comprehensive review of these formulae was reported by [6-8]. Subsequent modifications to these initial solutions have expanded their application conditions. Hantush $[9,10]$ addressed issues such as semi-confined or leaky conditions but they always assume a homogeneous system. More recent contributions have provided analytical solutions that deal with a complex aquifer by dividing it into several regions of homogenous properties, [11-15]. However, these analytical solutions cannot represent many important regional hydrologic features that affect groundwater movement such as aquifer anisotropy, structural features, recharge and discharge [16]. Adopting the analytical solutions to the design of dewatering systems assumes the validity of the cumulative/superposition approach. This approach implies that the drawdown at a given point due to several pumping wells at various distances apart equals the sum of the drawdowns from every single well if it was operated alone. Theoretically, superposition can be applied only when all hydraulic properties and boundary conditions remain constant during pumping [8]. For confined aquifers, cumulative drawdown analysis assumes that the wells do not interfere significantly. For wells installed at relatively wide spacing in confined aquifers and where the aquifers remain confined after drawdown, interference is not significant. Preene et al. [17] recommended multiplying the results of the superposition calculations for confined aquifers by an empirical superposition factor in the range of 0.8 to 0.95. If the aquifer is unconfined, or a confined aquifer becomes locally unconfined, the saturated thickness decreases as drawdown increases, that makes each additional well to become less efficient than the initial wells. For unconfined aquifers, the principle of superposition could be used where the reduction of the aquifer thickness by drawdown due to pumping did not exceed $20 \%$. Outside this drawdown limit, empirical superposition factors of 0.6 to 0.8 are recommended. The different formulae for calculating the cumulative drawdown in different aquifer conditions were presented by many authors [18, 19]. In general, analytical equations can, at best, give only estimated values of drawdown. Therefore, the use of these equations should be tempered with judgment based on experience in the project area [17] and/or adopting numerical modeling, [20].

This study aimed at investigating the suitability of the analytical equations to design groundwater lowering systems using deep pumping wells installed within the Egyptian aquifer areas mostly located in the Nile valley and Delta.

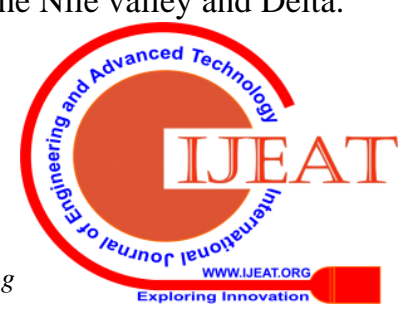


To achieve such a goal, the field dewatering data from different construction sites with different aquifer conditions were collected [20]. At each site, soil stratigraphy, deep wells arrangements, piezometer location, and readings, in addition to a pumping test data were gathered. The collected data were grouped into three categories according to the aquifer flow condition; gravity flow/ unconfined aquifer conditions, artesian flow/ confined aquifer conditions and mixed flow/ semi-confined conditions.

The pumping test at each site comprised in the current study was analyzed for estimating hydrogeological parameters such as average permeability, transmissivity and storage coefficient of aquifers [22, 23]. Also, a sensitivity study was conducted for each site to assess the influence of the aquifer thickness and permeability on the value of the cumulative drawdown. Making use of the measured in-situ transmissivity and in-situ drawdown, the cumulative drawdown factor, defined as the ratio of the assessed cumulative drawdown to the actual monitored value, was calculated for each site. An average/representative value of the cumulative drawdown factor for each type of the three aquifer flow conditions was established to enhance the reliability of the analytical equations in the analysis and design of dewatering systems within the Egyptian Nile Valley and Delta.

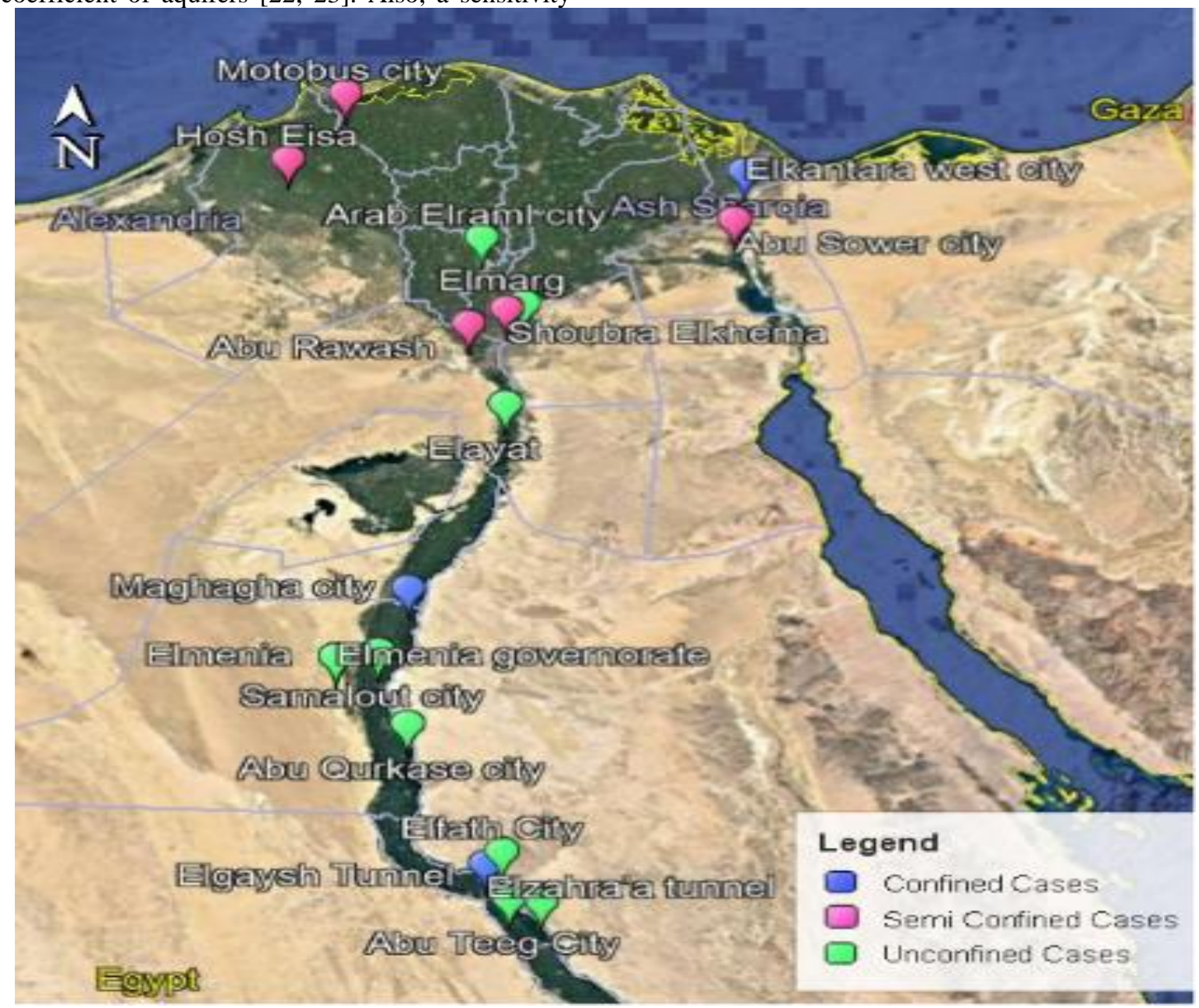

Fig. 1. Distribution of the in-situ monitored construction sites within Egypt.

\section{DESCRIPTION OF THE MONITORED SITES, PUMPING TESTS AND DEWATERING SYSTEMS}

The in-situ dewatering data from twenty construction sites within the Egyptian Nile valley and delta, Fig. 1, were collected and grouped according to their flow conditions. The in-situ dewatering cases were intended to cover the three categories of groundwater flow; gravity flow (10 unconfined aquifer conditions), artesian flow (5 confined aquifer conditions), and mixed flow (5 semi-confined aquifer conditions). For each of the considered construction sites, the field data from the borehole log, the performed pumping test, and the assembled dewatering system, were collected. The pumping test data were used to assess the influence radius $\mathrm{R}$, defined as the distance from the pumping well at which the drawdown equals zero. Also, the transmissivity parameter
(T), which is the coefficient of permeability times the aquifer thickness is determined, as will be discussed in the methodology.

\section{A. Gravity Flow Case Studies}




\begin{tabular}{|c|c|c|c|c|c|c|c|c|c|c|c|}
\hline \multicolumn{2}{|c|}{ Table- I: Data of the executed excavation, pumping test results, installed dewatering system, and the monitored drawdown values, in the } \\
investigated gravity aquifers, [21].
\end{tabular}

The description of the investigated sites that resemble unconfined flow conditions within /around the construction sites are summarized in table- I. The table includes; the intended exaction dimensions, pumping test results, number and length of deep wells, and the monitored drawdown value for each of the ten studied sites. The majority of the soil within all the monitored sites consist of sand formations with various grades and traces of silt. Fig. 2 shows a layout of the arrangement of wells and the location of the observation piezometer installed in the ten monitored sites.

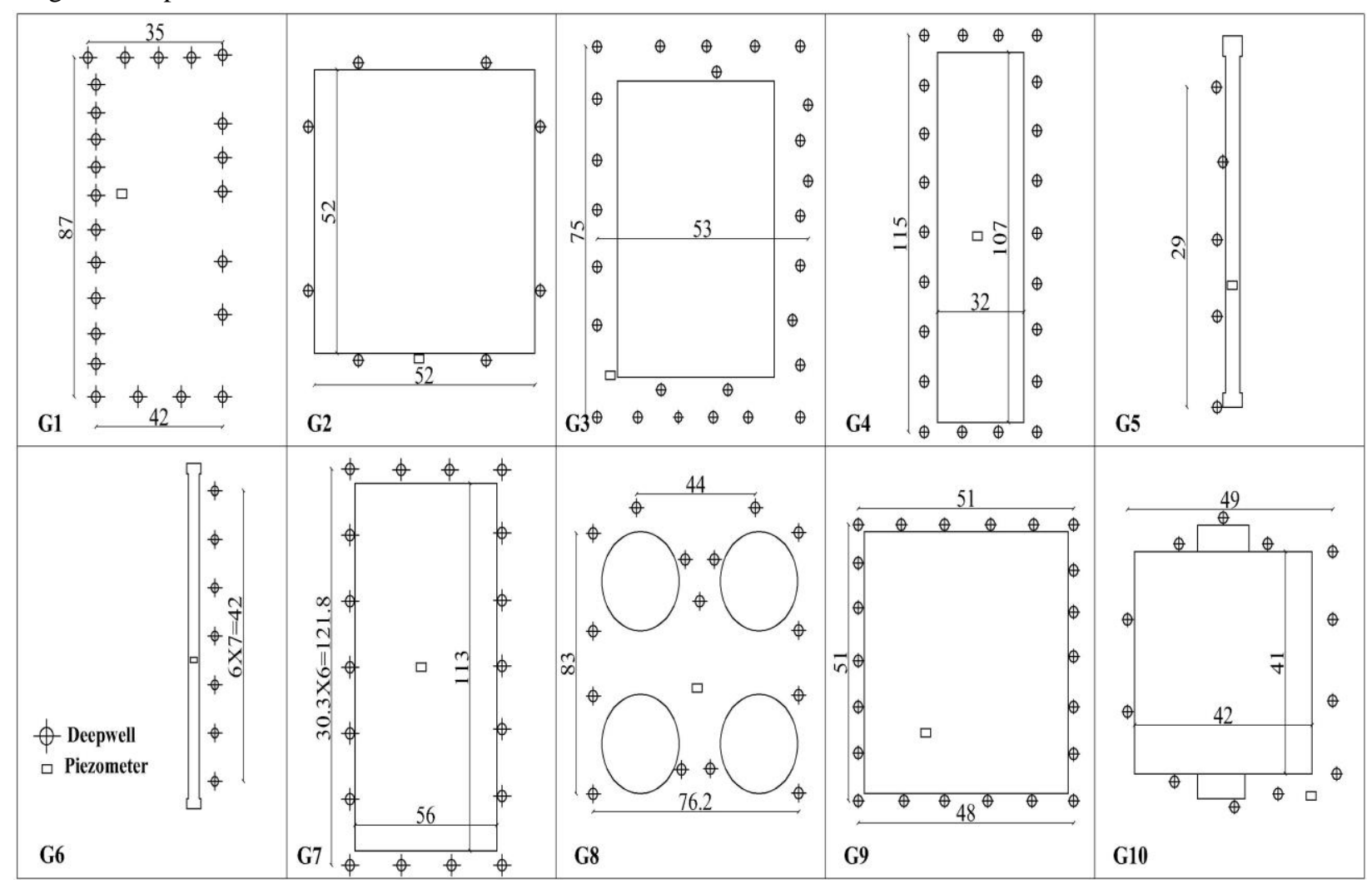

Fig. 2. Layout of the deep wells and observation piezometers at construction sites of the unconfined aquifers, [21].

\section{B. Artesian Flow Cases of Study}

The data of sites that resemble confined flow conditions within /around the construction sites, is presented in table- II. The table describes the excavation dimensions, the pumping test results, number and length of the deep wells, and the monitored drawdown value for each of the studied sites. The soil formations at all the sites consist meanly of a surface clay layer followed by a sand formation to the end of the borehole. Figure 3 shows a layout for the installed wells and the observation piezometer installed in each of the five monitored construction sites. 


\begin{tabular}{|c|c|c|c|c|c|c|}
\hline \multicolumn{7}{|c|}{ Table- II: Data of the investigated artesian aquifer sites, [21] } \\
\hline \multirow{2}{*}{\multicolumn{2}{|c|}{ Case Study }} & C1 & C2 & C3 & C4 & C5 \\
\hline & & 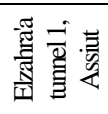 & 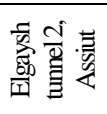 & 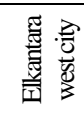 & 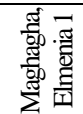 & 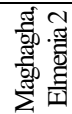 \\
\hline \multirow{3}{*}{ 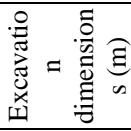 } & Width & 33 & 18 & 12.8 & 4.5 & 6 \\
\hline & Length & 73 & 71 & 22.8 & 6.7 & 6.5 \\
\hline & Depth & 6.65 & 7.5 & 2.5 & 7.4 & 6.2 \\
\hline \multicolumn{2}{|r|}{ Borehole length, (m) } & 20 & 20 & 10 & 10 & 10 \\
\hline \multicolumn{2}{|c|}{ Top clay layer depth $(\mathrm{m})$} & 13 & 13 & 3 & 8.3 & 8 \\
\hline \multicolumn{2}{|c|}{ G.W.L (m) } & 3 & 3 & 0.5 & 3 & 3 \\
\hline \multirow{3}{*}{ 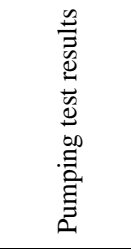 } & Discharge, Q (m³/hr) & 92.6 & 92.6 & 88.13 & 95.83 & 95.8 \\
\hline & Transmissivity T, (m²/day) & 890 & 930 & 1870 & 740 & 685 \\
\hline & Influence Radius R, (m) & 210 & 210 & 160 & 360 & 360 \\
\hline \multirow{3}{*}{ 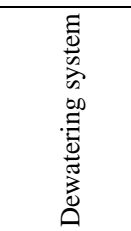 } & No. of deep wells & 9 & 11 & 12 & 3 & 3 \\
\hline & Length of wells (m) & 20 & 20 & 18 & 23 & 20 \\
\hline & drawdown at piezometer (m) & 4.15 & 6.3 & 2.9 & 5.1 & 5 \\
\hline
\end{tabular}

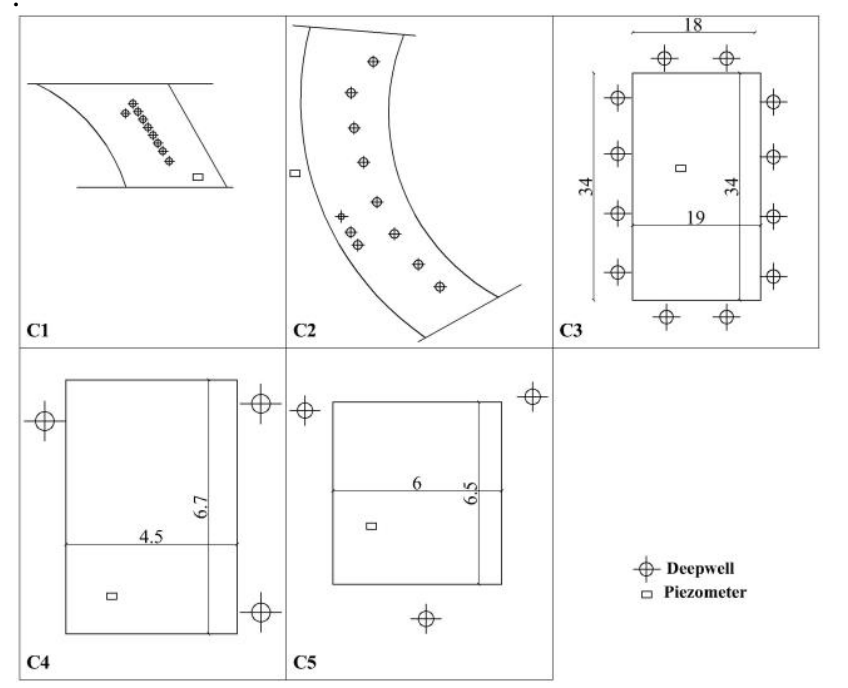

Fig. 3. Layout of the deep wells and observation piezometers arrangement the confined aquifers sites, [21].

\section{Mixed Flow Case Studies}

A semi-confined aquifer is an aquifer bounded at the top by soil layers of relatively low permeability, especially in horizontal sense. The free water table is observed within this top layer and its flow is mainly vertical. Table- III presents the site conditions of the semi-confined aquifers within /around the construction sites for each of the considered cases. The table describes the soil formation, the excavation dimensions, the pumping test results, number and length of the wells, and the monitored drawdown value for each of the studied sites. The borehole logs show that the soil formations at all sites consist of a surface clay layer followed by a sand formation to the end of the borehole. Fig. 4 shows a layout of the arrangement of wells and the location of the observation piezometer installed in the five monitored construction sites.
Table- III: Data of the investigated mixed aquifer sites, [21].

\begin{tabular}{|c|c|c|c|c|c|c|}
\hline & Case Study & M1 & M2 & M3 & M4 & M5 \\
\hline & Location & 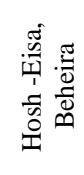 & 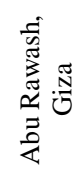 & 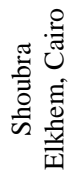 & 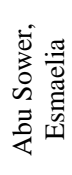 & 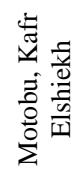 \\
\hline & Width & 5 & 72 & 3 & 12 & 3 \\
\hline$\sum_{0}^{\pi} \cdot \frac{a}{0}$ & Length & 25 & 85 & 90 & 100 & 35 \\
\hline 되 은 & Depth & 5.5 & 10.6 & 6.7 & 5 & 6 \\
\hline Bor & ehole length, (m) & 15 & 20 & 20 & 15 & 15 \\
\hline Top c & $\begin{array}{l}\text { lay/ silty clay layer } \\
\text { thick. (m) }\end{array}$ & 1.4 & 5.5 & 4 & 2.7 & 3 \\
\hline & G.W.L (m) & 0.4 & 5.6 & 2 & 0.4 & 1.5 \\
\hline$\frac{n}{\overrightarrow{3}}$ & $\begin{array}{c}\text { Discharge, } Q \\
\left(\mathrm{~m}^{3} / \mathrm{hr}\right)\end{array}$ & 113.6 & 95.83 & 106 & 98.3 & 92.6 \\
\hline 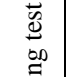 & $\begin{array}{l}\text { Transmissivity } \\
\mathrm{T},\left(\mathrm{m}^{2} / \text { day }\right)\end{array}$ & 1420 & 1710 & 1840 & 2000 & 1180 \\
\hline 宝 & $\begin{array}{c}\text { Influence Radius } \\
\text { R, (m) }\end{array}$ & 140 & 290 & 320 & 200 & 355 \\
\hline छ్ & $\begin{array}{l}\text { No. of deep } \\
\text { wells }\end{array}$ & 10 & 22 & 11 & 19 & 6 \\
\hline $\begin{array}{l}5 \\
00 \\
.0\end{array}$ & $\begin{array}{l}\text { Length of wells } \\
\text { (m) }\end{array}$ & 21 & 24 & 20 & 21 & 19 \\
\hline ڤัٌ & $\begin{array}{c}\text { drawdown at } \\
\text { piezometer (m) }\end{array}$ & 6.2 & 6.15 & 5.5 & 5.21 & 5.75 \\
\hline
\end{tabular}




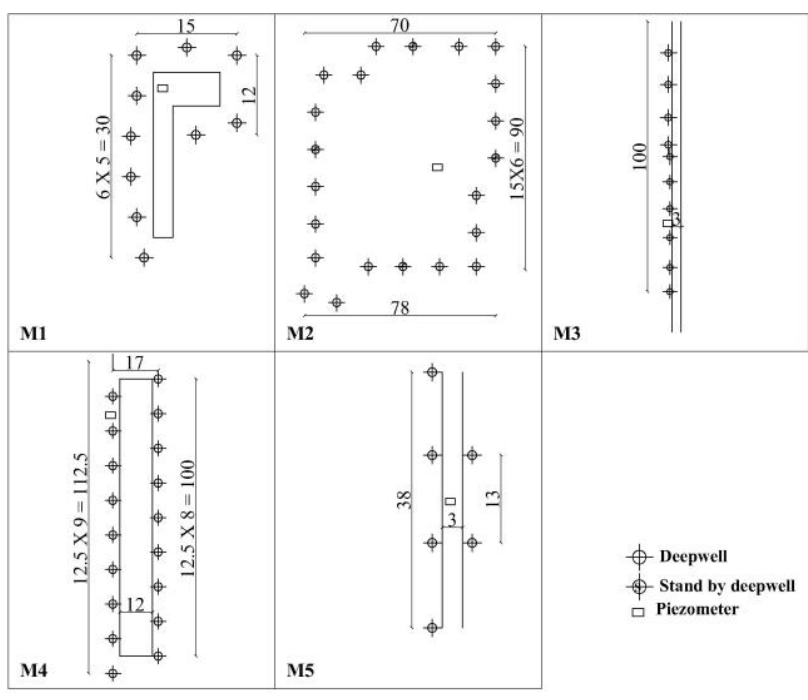

Fig. 4. Layout of the deep wells and observation piezometer arrangement in the mixed aquifers sites, [21].

\section{METHODOLOGY}

\section{A. Empirical Equations}

Analytical equations that are commonly used for studying the responses of dewatering systems, were reported by [17, 18]. In the current study, quations 1 to 3 were adopted to the considered in-situ cases in order to evaluate the reliability of such emperical equations in predicting groundwater performane. In view of the superpostion/cumulative drawdown concept, the following equations were used to estimate the total drawdown at any point within construction sites for gravity, artesian and mixed flow conditions, respectively:

For gravity flow

$$
(H-h)=\frac{Q P \ln (10 R / H)}{\pi K H\left[1-0.8(S / H)^{1.5}\right]}
$$

For artesian flow

$(H-h)=\left(\frac{Q}{2 \pi K D}\right) \sum \ln (R / r)$

For mixed flow

$$
(H-h)=H-\sqrt{\left[2 H D-D^{2}-\left(\frac{Q}{\pi K}\right) \sum \ln R / r\right]}
$$

\begin{tabular}{|c|c|c|}
\hline H-h: & & Analytical drawdown at distance r, (m) \\
\hline $\mathrm{H}$ & : & \\
\hline Q & : & The recorded discharge rate, $\left(\mathrm{m}^{3} / \mathrm{hr}\right)$ \\
\hline $\mathrm{K}$ & : & Coefficient of permeability, (m/ sec) \\
\hline $\mathrm{R}$ & : & $\begin{array}{l}\text { The radius of influence, }(\mathrm{m}) \\
\end{array}$ \\
\hline $\mathrm{D}$ & : & \\
\hline $\mathrm{P}$ & : & A constant having a value of $[0.13 \Sigma \ln (\mathrm{R} / \mathrm{r})]$, \\
\hline S & : & $\begin{array}{l}\text { The difference between the aquifer thickness } \\
\text { and the well depth, (m) }\end{array}$ \\
\hline $\mathrm{T}$ & : & The transmissivity ( $\mathrm{T}=\mathrm{K} . \mathrm{D}),\left(\mathrm{m}^{2} /\right.$ day) \\
\hline
\end{tabular}

In which:

\section{B. In-Situ Data Analysis and Sensitivity Study}

Analyses were carried out for the investigated in-situ dewatering cases that belong to the three categories of groundwater flow; gravity, artesian and mixed flow. The objective of these analyses is to compare the results of the analytical solutions with the monitored responses to evaluate the adequacy of emperical equations for assessing the performance of the assembled dewatering systems, in terms of a cumulative drawdown factor (CDF), for each site/category of groundwater flow. The analysis was performed through the following two phases:

\section{Pumping Test Data Analysis:}

For each construction site, the recorded pumping test data was analysed to assess the equivalent radius of influence (R) and the actual transmissivity (T), given in Tables 1 to 3 , as follows:

- The equivalent radius of influence $(R)$ is obtained in the current analysis by plotting the observed drawdown versus the distance to the pumping well on a semi-log scale. The value of $(\mathrm{R})$ will be the distance from the pumping well at which the drawdown equals zero.

- The transmissivity parameter $(\mathrm{T})$, which is the coefficient of permeability times the aquifer thickness, is also used in the analysis of results. For each case, the actual transmissivity is obtained from the pumping test data based on the Cooper and Jacob (1946) method by plotting the observed drawdown versus the time, on a semi-log scale, during a constant discharge rate $(\mathrm{Q})$. The transmissivity is calculated from $(\mathrm{T}=2.303 \mathrm{Q} / 4 \pi \Delta \mathrm{s})$, where $(\Delta \mathrm{s})$ is the slope of the fitted line.

\section{Sensitivity Study:}

In all the in-situ considered cases, the site investigation boreholes did not extend to reach the bottom of the aquifer layer, which is a typical practice. For unconfined aquifers, the thickness of the really hydraulically active part of the aquifer is also undefined. Therefore, a sensitivity study to show the impact of both the aquifer thickness (D) and the permeability coefficient $(\mathrm{K})$, on the calculated drawdown values was conducted by adopting the suitable emperical equation. The in-situ recorded discharge rate for each site was also implemented in all calculations through the following steps:

- For each site, different values of the aquifer thickness (D), ranging from 1 to more than 2 times the penetration depth of the well, were investigated, as stated in the next sections.

- The different predicted drawdown values corresponding to each set of the investigated parameters, (D) and (K), were used to assess the corresponding cumulative drawdown factor (C.D.F), defined as the ratio of the actual drawdown to the analytically estimated value.

- For each site, an interdependent relationship was graphically established by plotting the transmissivity ( $\mathrm{T}=$ KD) against the assessed (C.D.F), Figs. 5 to 7. 

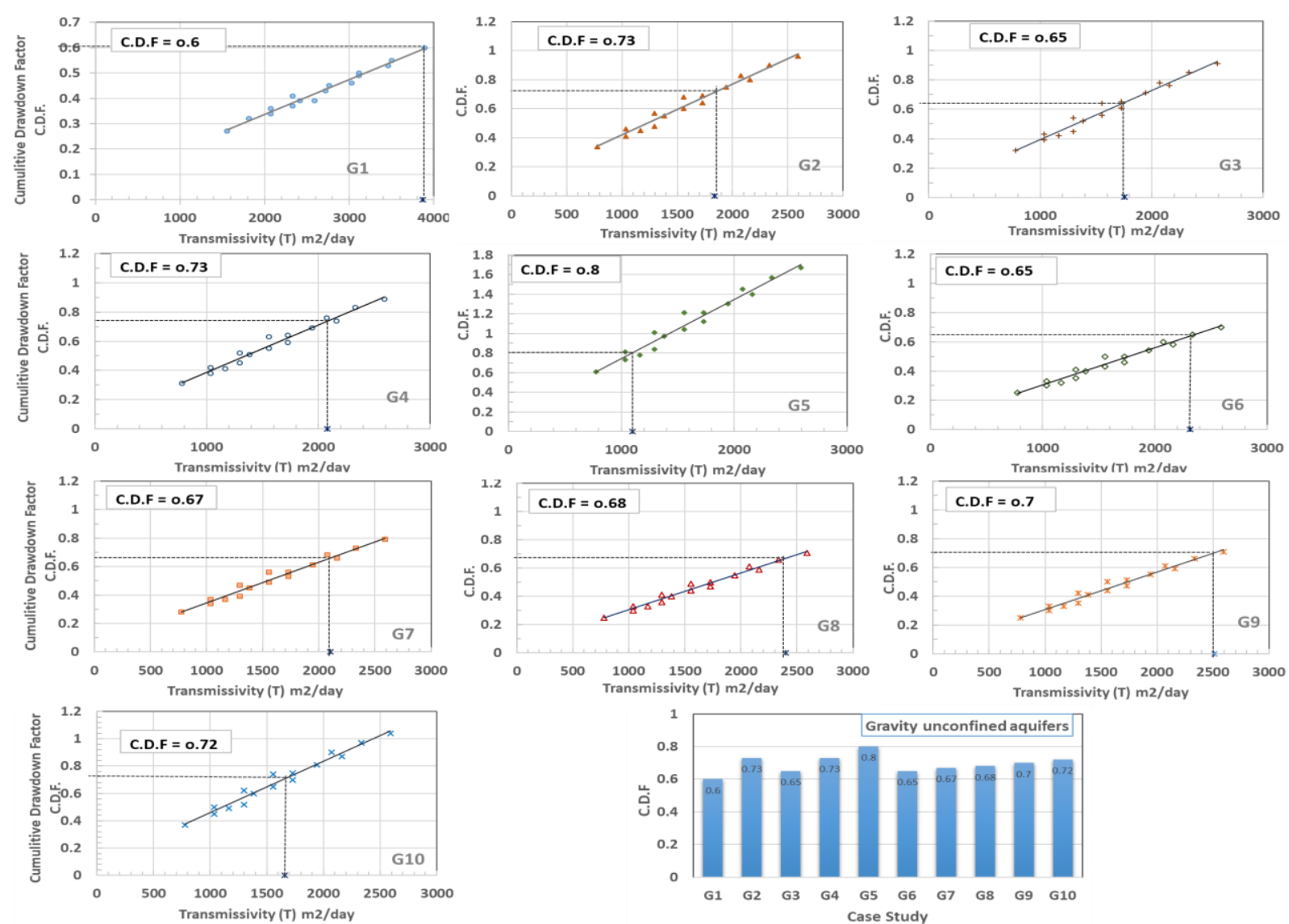

Fig. 5. The relationship of the transmissivity versus the cumulative drawdown factor, for gravity/unconfined aquifer sites \& All the derived actual C.D.Fs for sites (G1- G10)

The trendline of this relationship together with the monitored in-situ transmissivity $(\mathrm{T})$ allowed for estimation of the actual cumulative drawdown factor (C.D.F) for the site under consideration as shown in Figs. 5 to 7.

- An avarege value of the cumulative drawdown factor (C.D.F) was then, derived for each aquifer category.

\section{ANALYSIS OF RESULTS}

\section{A. The Unconfined Aquifers}

For the analysis of the considered unconfined aquifer cases, equation (1) was adopted to assess the analytical/theoretical drawdown value at any point within the excavation vicinity.

It is worth mentioning that, equation (1) has resulted in more accurate results than the basic equation, recorded by [17], when applied to the considered gravity aquifer cases.

The sensitivity study for the investigated gravity flow cases was conducted by considering different values of the aquifer thickness (ranging from $30 \mathrm{~m}$ to $50 \mathrm{~m}$ ) and the coefficient of permeability (ranging from 3E-4 m/sec to $9 \mathrm{E}-4$ $\mathrm{m} / \mathrm{sec}$ ). Fig. 5 compiles the results of the sensitivity analysis conducted for the gravity aquifers, where variations of the calculated cumulative drawdown factors (C.D.F) were plotted against the corresponding assessed transmissivity (T). The figure exhibits that a linear relationship can be considered to represent the transmissivity versus C.D.F. Consequently, by adopting the in-situ actual transmissivity of the site under consideration, the actual site cumulative drawdown factor (C.D.F) can be assessed.

The actual values of the cumulative drawdown factor for the considered sites are also graphically presented. It can be noticed that the cumulative drawdown factor varies from around 0.6 to 0.8 , with an average value of 0.7 . In other words, on designing a dewatering system where the construction site is found in an area where unconfined conditions exist, the analytically estimated drawdown using the superposition / cumulative approach should be multiplied by a factor equal to around 0.7 . The average value of the C.D.F was admired in the current study because it is, statistically, the most representative value for such one-dimensional variable.

The obtained C.D.F values agree well with the empirical superposition factors of $0.6-0.8$, suggested by [17]. These factors, besides considering the interference between wells, they also account for the reduction in the saturated well thickness with increasing the drawdown, that reduces the efficiency of each additional well.

\section{B. The Confined Aquifers}

Equation (2) was used for the analysis of the considered confined aquifer cases to calculate the analytical drawdown value at any point within the excavation vicinity. The sensitivity study considering different values of the aquifer thickness (ranging from $14 \mathrm{~m}$ to $50 \mathrm{~m}$ ) and the coefficient of permeability (ranging from $3 \mathrm{E}-4 \mathrm{~m} / \mathrm{sec}$ to $6 \mathrm{E}-4 \mathrm{~m} / \mathrm{sec}$ ), was conducted for each case/site, to investigate their impact on the calculated drawdown.

Published By:

Blue Eyes Intelligence Engineering 
The results of the sensitivity analysis conducted on the artesian aquifer cases are compiled in Fig. 6. The figure shows the variation of the calculated cumulative drawdown factor (C.D.F) with the corresponding calculated transmissivity $(\mathrm{T})$, for each of the investigated cases. The figure delineates a linear relationship between the transmissivity and the C.D.F. Consequently, by using the in-situ actual transmissivity of the site under consideration, the corresponding actual site cumulative drawdown factor (C.D.F), can be assessed.

The values of the actual cumulative drawdown factor for the considered different sites, are also presented in Fig. 6 . The obtained actual cumulative drawdown factors for the confined flow sites vary from around 0.5 to 0.76 , with an average value of 0.65 . Therefore, on designing a dewatering system in confined aquifer conditions, it is recommended to multiply the analytically estimated drawdown using the superposition cumulative approach, by a factor that equals 0.65. The C.D.F values derived for the considered construction sites is lower than the empirical superposition factor (0.8 to 0.95 ) recommended by [17].

\section{The Mixed Aquifers}

For analyzing the studied mixed aquifers, equation (3) was implemented to assess the analytical drawdown value at any point within the excavation area. A sensitivity study considering different values of the aquifer thickness (ranging from $30 \mathrm{~m}$ to $50 \mathrm{~m}$ ) and the coefficient of permeability (ranging from $3 \mathrm{E}-4 \mathrm{~m} / \mathrm{sec}$ to $6 \mathrm{E}-4 \mathrm{~m} / \mathrm{sec}$ ), was conducted for each case/site, to investigate their impact on the calculated drawdown.

The sensitivity analysis results are compiled in Figs. 7. As discussed in the previous cases, the in-situ actual transmissivity value for each of the considered sites was adopted to assess the corresponding actual site cumulative drawdown factor (C.D.F). As shown in Fig. 7, the cumulative
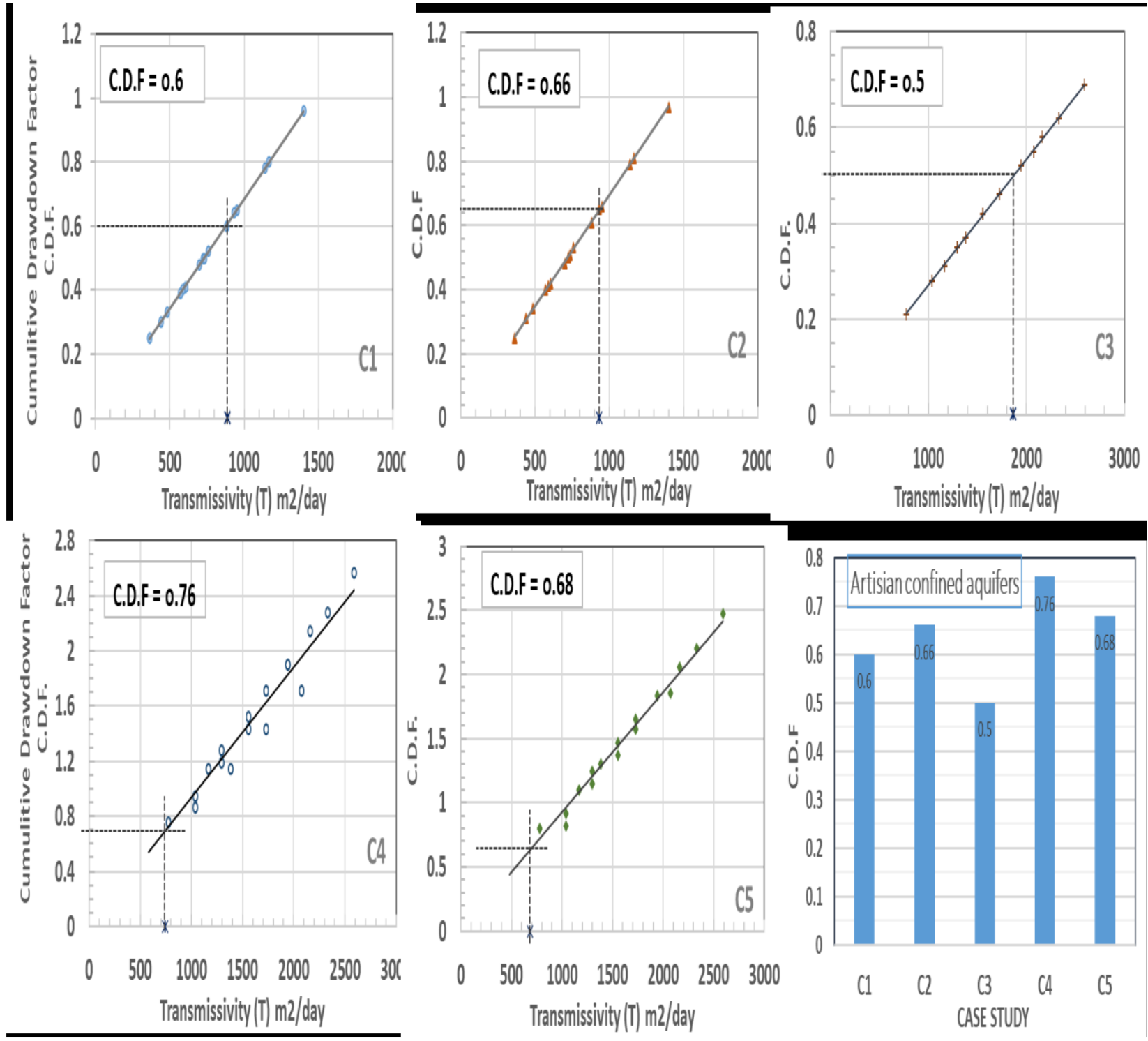

Fig. 6 The relationship of the transmissivity versus the cumulative drawdown factor, for artesian/confined aquifer sites \& All the derived actual C.D.Fs for sites (C1- C5) 

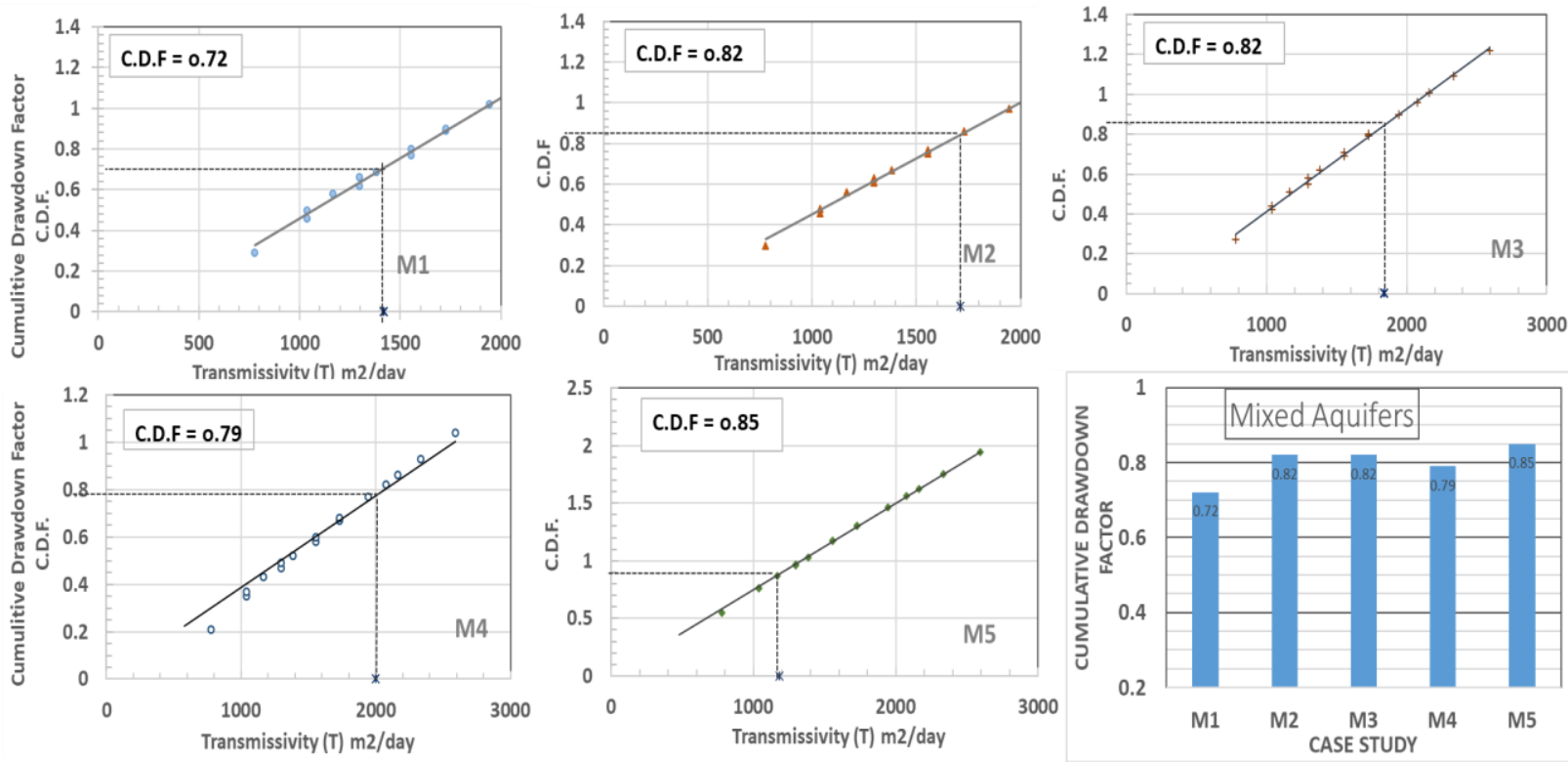

Fig. 7. The relationship of the transmissivity versus the cumulative drawdown factor, for mixed/ mixed aquifer sites \& All the derived actual C.D.Fs for sites (M1- M5)

Drawdown factor for the mixed flow sites varies from around 0.72 to 0.85 , with an average value of 0.8 . Therefore, a correction factor of 0.8 is recommended to enhance the drawdown that is analytically estimated using the superposition cumulative approach.

Table III compiles the results of the above-mentioned comprehensive study that integrates the field observations in order to judge the reliability of the analytical models. It is obvious that, these models mostly overestimate the predicted drawdown values in different types of flow condition. As previously discussed, this can be attributed to the interference between the influence zones of the pumping wells, which is not taken into consideration in applying the superposition concept.

Table- III: Concluded results for all the examined cases.

\begin{tabular}{|c|c|c|c|c|c|}
\hline \multicolumn{6}{c|}{ Unconfined Aquifers } \\
\hline Case & G1 & G2 & G3 & G4 & G5 \\
\hline $\begin{array}{c}\text { In-situ } \\
\text { (T), } \\
\mathrm{m}^{2} / \text { day }\end{array}$ & 3870 & 1840 & 1760 & 2080 & 1100 \\
\hline $\begin{array}{c}\text { The Site } \\
\text { C.D.F. }\end{array}$ & 0.6 & 0.73 & 0.65 & 0.73 & 0.8 \\
\hline Case & G6 & G7 & G8 & G9 & G10 \\
\hline $\begin{array}{c}\text { In-situ } \\
\text { (T), } \\
\mathrm{m}^{2} / \text { day }\end{array}$ & 2315 & 2100 & 2400 & 2510 & 1660 \\
\hline $\begin{array}{c}\text { The Site } \\
\text { C.D.F. }\end{array}$ & 0.65 & 0.67 & 0.68 & 0.7 & 0.72 \\
\hline
\end{tabular}

\begin{tabular}{|c|c|c|c|c|c|}
\hline \multicolumn{7}{|c|}{ Confined Aquifers } \\
\hline Case & C1 & C2 & C3 & C4 & C5 \\
\hline $\begin{array}{c}\text { In-situ } \\
\text { (T), } \\
\text { mday }\end{array}$ & 890 & 930 & 1870 & 740 & 685 \\
\hline $\begin{array}{c}\text { The Site } \\
\text { C.D.F. }\end{array}$ & 0.6 & 0.66 & 0.5 & 0.76 & 0.68 \\
\hline
\end{tabular}

\begin{tabular}{|c|c|c|c|c|c|}
\hline \multicolumn{7}{|c|}{ Semi-Confined Aquifers } \\
\hline Case & M1 & M2 & M3 & M4 & M5 \\
\hline $\begin{array}{c}\text { In-situ } \\
\text { (T), } \\
\mathrm{m}^{2} \text { day }\end{array}$ & 1420 & 1710 & 1840 & 2000 & 1180 \\
\hline $\begin{array}{c}\text { The Site } \\
\text { C.D.F. }\end{array}$ & 0.72 & 0.82 & 0.82 & 0.79 & 0.85 \\
\hline
\end{tabular}

\section{SUMMARY AND CONCLUSIONS}

This study has been performed to evaluate the adequacy of the analytical empirical equations commonly adopted to design groundwater control systems in different aquifer conditions. To assure the reliability of such evaluation, the field dewatering data collected from 20 different construction sites within Egypt, was processed to assess a correlative factor, C.D.F, for each category of groundwater flow. Average cumulative drawdown factors of $0.7,0.65$ and 0.8 , are recommended to enhance the mathematically predicted drawdown values within unconfined, confined and semi-confined aquifers, respectively.

The most important outcome of this study is that, care must be taken when implementing the analytical empirical equations in designing the dewatering systems. Also, the aquifer parameters adopted in the empirical equations should carefully be selected. The established cumulative drawdown factors (C.D.F) would be suitable for application, specifically, in the Nile valley and Delta regions.

\section{REFERENCES}

1. K. M., "Rathfelder, Modelling tools for estimating effects of groundwater pumping on surface waters", Province of British Columbia, Ministry of Environment, Water Science Series WSS2016-09, 2016.

2. G. Thiem, Hydrologische Methoden. JM Gebhardt, Leipzig, 1906.

3. C. V. Theis, "The relation between the lowering of the piezometric surface and the rate and duration of discharge to a well using groundwater storage", Trans. of the American Geophysical Union, 1935, pp. 519-524.

4. H. H. Cooper and C. E. Jacob, "A generalized graphical method for evaluating formation constants and summarizing well field history", Am. Geophysics. Union Trans., 1946, vol. 27, pp. 526-534.

5. F. G. Driscoll, Groundwater \& wells, Johnson Filtration Systems, St Paul, MN, 1986. 
6. C. Mansur and R. Kaufman, "Dewatering in Foundation Engineering”, in G. Leonard (Editor): Foundation Engineering, McGraw-Hill, New York, 1962.

7. M. R. Hausmann, "Engineering Principles of Ground Modification", McGraw-Hill, New York, 1990.

8. J. P. Power, "Construction Dewatering- New Methods and Applications”, John Wiley \& Sons, New York, 1992.

9. M. S. Hantush, "Modification of the Theory of Leaky Aquifers", $J$. Geophysical Research, Vol. 65, 1965, pp. 3713-3725.

10. M. S. Hantush, "Analysis of Data from Pumping Tests in Anisotropic Aquifers”, J. Geophysical Research, Vol. 71, 1966, pp. 421-426.

11. J. A. Barker, "A generalized Radial Flow Model for Hydraulic Test in Fracture Rock”, Water Resources Research J., Vol. 24, 1988, pp 1796-1804.

12. J. J. Jr. Butler, "Pumping Tests in Non-Uniform Aquifer: The Radially Symmetric Case", J. of Hydrology, Vol. 125, 1988, pp. 15-30.

13. J. J. Jr. Butler and W. Z. Lui, "Pumping Tests in Non-Uniform Aquifers - The Linear Strip Case”, J. of Hydrology, Vol. 128, 1991, pp. 69-99.

14. J. J. Jr. Butler and W. Z. Liu, "Pumping Tests in Non-Uniform Aquifer: The Radially Asymmetric Case", Water Resources Research J., Vol. 29 (1993), No. 2, pp. 259-269.

15. Liang Xiao, "Evaluation of Groundwater Flow Theories and Aquifer Parameters Estimation". Dissertation submitted to the University of the Western Cape, 2014, Cape Town, South Africa.

16. C. Ardito, D. Jordan, M. Lavenue and G. Ruskauff, "Requirements for Defensible Groundwater Modeling”, NGWA Groundwater and Environmental Law Conference, Chicago, Illinois, 2004.

17. M. Preene, T. O. L. Roberts, W. Powrie, and M. R. Dyer, "Groundwater Control - Design and Practice”, CIRIA Report No. C115, 2000.

18. J. P. Powers, A. B. Corwin, Paul C. Schmall and W. E. Kaeck, "Construction Dewatering and Groundwater Control: New Methods and Applications”, Third Edition. Copyright (C) 2007 John Wiley \& Sons, Inc. ISBN: 978-0-471-47943-7.

19. G. A. Leonards, ed., 1962, "Foundation Engineering," McGraw-Hill Book Company.

20. A.M. Samieh, M.A. Mansour, A.O. Hindi, and A.M.H. Mahmoud, "Modeling of Groundwater Flow in Mixed Aquifers", Proc of the Sixth Alexandria International Conference of Structural and Geotechnical Engineering, Alexandria, Egypt, 2007, pp. GT37-GT51.

21. A. A. Eslam, "Evaluation of Dewatering Systems Using In-Situ Collected Data”, MSc. Thesis in Civil Engineering, 2009, Helwan University, Cairo, Egypt.

22. M. L. Calvache, J. P. Sánchez-Úbeda, C. Duque, M. López-Chicano and B. de la Torre, "Evaluation of Analytical Methods to Study Aquifer Properties with Pumping Tests in Coastal Aquifers with Numerical Modelling (Motril-Salobreña Aquifer)". Water Resources Manage., 2016, 30:559-575, DOI 10.1007/s11269-015-1177-6.

23. D. K. Mawlood and J. S. Mustafa, 2016, "Performing Pumping Test Data Analysis Applying Cooper-Jacob's Method for Estimating of the Aquifer Parameters", Mathematical Modelling in Civil Engineering, Vol. 12-No. 1: 9-20 - 2016, Doi: 10.1515/mmce-2016-0006.

\section{AUTHORS PROFILE}

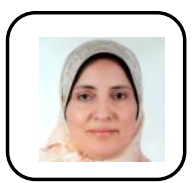

Mona A. Mansour is an Associate Professor in Civil ngineering Department, Helwan University, Cairo, Egypt. She is specialized in Geotechnical engineering. She has received her $\mathrm{PhD}$. degree from the University of Innsbruck, Innsbruck, Austria in 1996. She is a member of the Egyptian chapter of the "International Society for Soil Mechanics and Geotechnical Engineering" (ISSMGE). Also, a member of the Egyptian chapter of "International Geosynthetics Society" (IGS).

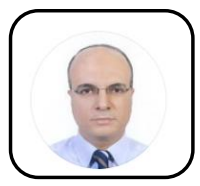

Ahmed M. Samieh is a Professor of Geotechnical Engineering, Civil Engineering Department, Faculty of Engineering at Mataria, Helwan University, Cairo, Egypt. He has received the $\mathrm{PhD}$. degree from the University of Calgary, Calgary, Canada in 1995. He is a member of the International Society for Soil Mechanics and Geotechnical

Engineering" (ISSMGE), the Egyptian chapter.

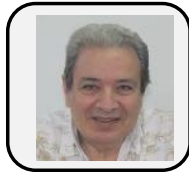

Amr Radwan is a Professor of Geotechnical Engineering, Civil Engineering Department, Faculty of Engineering at Mataria, Helwan University, Cairo, Egypt. He has published several books in geotechnical engineering. He has been teaching, contributing in researches, supervising post-graduate students for more than 35 years. He is a member of the Egyptian chapter of the "International Society for Soil Mechanics and Geotechnical Engineering" (ISSMGE).

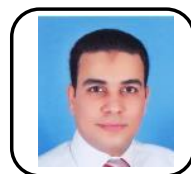

Eslam A. Ahmed is an engineer in the Ministry of Housing, Utilities and Urban Communities, Egypt. He is now a project follow-up engineer in the Construction sector. He has received his M.Sc. degree from Helwan University in 2009. 